OPEN ACCESS

Edited by:

Lorys Castelli,

University of Turin, Italy

Reviewed by:

Charlotte Ulrikka Rask,

Aarhus University Hospital, Denmark

Joana Carvalho,

Universidade Lusófona, Portugal

*Correspondence:

Ingrid Banovic

Ingrid.Banovic@univ-rouen.fr

Specialty section:

This article was submitted to

Health Psychology,

a section of the journal

Frontiers in Psychology

Received: 22 December 2019

Accepted: 23 March 2020

Published: 30 April 2020

Citation:

Banovic I, Montreuil L, Derrey-Bunel M, Scrima F, Savoye G,

Beaugerie L and Gay M-C (2020)

Toward Further Understanding of Crohn's Disease-Related Fatigue:

The Role of Depression and Emotional

Processing. Front. Psychol. 11:703.

doi: 10.3389/fpsyg.2020.00703

\section{Toward Further Understanding of Crohn's Disease-Related Fatigue: The Role of Depression and Emotional Processing}

\author{
Ingrid Banovic ${ }^{*}$, Louise Montreuil' ${ }^{1}$, Marie Derrey-Bunel ${ }^{2}$, Fabrizio Scrima ${ }^{1}$, \\ Guillaume Savoye $^{3}$, Laurent Beaugerie ${ }^{4}$ and Marie-Claire Gay ${ }^{5}$
}

'CRFDP (EA7475), Rouen Normandy University, UFR SHS, Mont-Saint-Aignan, France, ${ }^{2}$ CRFDP (EA7475), Rouen Normandy University, Hôpital Jacques Monod, Montivilliers, France, ${ }^{3} \mathrm{CHU}$ Charles Nicolles, Rouen, France, ${ }^{4}$ Hôpital Saint-Antoine, Paris, France, ${ }^{5}$ CLIPSYD (EA4430), Paris Nanterre University, Nanterre, France

Because the relationship between Crohn's Disease (CD) activity and CD-related fatigue remains poorly understood, this study investigated the role of underlying psychological processes (depression, anxiety, and emotional processing). It was expected that the relationship between CD activity and CD-related fatigue would be mediated by depression and anxiety and also by a deficit in emotional processing. This prediction was tested in $110 \mathrm{CD}$ patients who completed self-reported questionnaires assessing fatigue (FSS), clinical activity of Crohn's Disease (HBAI), psychological suffering (HADS), and emotional processing (EPS-25). A path analysis showed both direct and indirect effects in the relationship between CD activity and CD-related fatigue, accounting for $33 \%$ of the variance. One indirect effect on the experience of fatigue was depression, but there was no effect of anxiety. These preliminary results confirmed that disease activity induces an increase in depressive symptoms, which in turn leads to an increase in the level of fatigue. The most novel result of the present study is that emotional processing had an indirect effect on the relationship between CD and CD-related fatigue: when the disease was more active, patients exhibited greater disruption of emotional processing, which in turn led to greater fatigue. These results did not reveal any association between depression and emotional processing. In conclusion, this work highlights the role of emotional processing in CD-related fatigue and the importance of taking this factor into account in order to manage this condition better.

Keywords: fatigue, Crohn's Disease, disease activity, emotional processing, depression, anger

\section{INTRODUCTION}

Crohn's Disease (CD), like all types of Inflammatory Bowel Disease (IBD), is characterized by chronic, recurrent inflammation of the gastrointestinal tract that causes the most common symptoms: diarrhea, blood and mucus in the stool, and abdominal cramping. It can also cause systemic symptoms outside the gastro-intestinal tract, such as redness or pain in the eyes, mouth sores, painful joints, skin complications, and fatigue. 
Fatigue is defined as a persistent and overwhelming sense of tiredness, weakness, or exhaustion, which can be mental, physical or both (Artom et al., 2016). It is not therefore surprising that $\mathrm{CD}$ patients describe fatigue as one of their most troublesome symptoms (Wåhlin et al., 2019). Although its prevalence in patients with an active disease has been reported to be as high as $86 \%$, fatigue related to CD is still poorly understood. For example, because fatigue is known to be more acute when CD is clinically active (Dignass et al., 2010; Czuber-Dochan et al., 2013b; Graff et al., 2013; van Langenberg and Gibson, 2014), it is often viewed as a direct consequence of disease activity (Opheim et al., 2014; Artom et al., 2017); and yet, CD-related fatigue actually persists in $22-41 \%$ of patients in clinical remission (Jelsness-Jørgensen et al., 2011; Czuber-Dochan et al., 2013b).

Past research addressing the issue of fatigue in CD has established a link between depression and anxiety symptoms and CD-related fatigue (Banovic et al., 2012; Mikocka-Walus et al., 2016; Neuendorf et al., 2016; Borren et al., 2019). More specifically, depressive symptoms seem to be more apparent when the disease is active or when patients present an inflammatory state (Neuendorf et al., 2016; Abautret-Daly et al., 2018). Even though depressive symptoms are - at least partly due to the course of the disease, it is unlikely that the relationship between $\mathrm{CD}$ activity and fatigue can be fully mediated by these symptoms, for at least two reasons. First, the prevalence of fatigue that affects between 44 and $86 \%$ of CD patients (depending on the study and methodology) exceeds the prevalence of depressive and anxiety symptoms that are found in about 30\% of these patients (Goodhand et al., 2012). Secondly, 22\% of CD patients in remission still report symptoms of depression, and $41 \%$ report symptoms of anxiety (Keeton et al., 2015).

Studies of Multiple Sclerosis (MS), another inflammatory autoimmune disease, have shown that emotional processing in people with MS is more dysfunctional compared to healthy controls (Gay et al., 2019). They show how anxiety may affect depression directly, through unregulated emotions, and indirectly, by generating negative emotions (Gay et al., 2010, 2017). These results are similar to those obtained in a study with IBD patients, which found that less positive emotion recognition mediated the effects of disease activity on depression (Wilkinson et al., 2019). These difficulties in emotional processing would explain the higher rates of depression among people with these diseases. In line with Baker et al. (2010) model of emotional processing (see also Rachman, 1980), concerns associated with the daily management of $\mathrm{CD}$ would contribute to fatigue, taking the form of intrusive and/or repetitive thoughts that are associated with negative emotions when different stages of emotional processing (i.e., registration, appraisal, experience, awareness, and expression of emotions) are impeded. Therefore, it is plausible that the link between CD activity and fatigue is due (at least in part) to disrupted emotional processing. The outcome of CD activity would lead patients to focus on their physical condition to the detriment of taking into account their emotional states. Having relatively little direct control over the medical situation could lead to anxious ruminations and suppression of emotions in order to avoid adding emotional distress to the physical suffering. All of which would lead to a state of fatigue.
In line with past findings, e expected that the link between clinical activity of the disease and fatigue would be mediated by the severity of depression and anxiety symptoms. More importantly, we also expected to observe that emotional processing would be more dysfunctional when the disease is clinically active, leading to greater CD-related fatigue. In other words, we expected that the link between clinical activity of the disease and CD-related fatigue would be mediated by the severity of emotional dysregulation Finally, we expected these mediators to be intercorrelated and the main objective of the study was to examine their respective relative weight in the association between clinical activity of the disease and CD-related fatigue. (cf. Figure 1).

\section{MATERIALS AND METHODS}

\section{Participants, Recruitment and Procedure}

The 110 volunteer CD patients were recruited between June 2016 and June 2017 in two hospitals: (1) a referral center for the medical management of IBD, and (2) the gastroenterology department of a teaching hospital in a medium-sized provincial city in France. They were aged 18 years or older and had a medical diagnosis of CD; $50 \%$ of the sample had an active disease (see Table 1). Participants completed the entire questionnaire when they attended the hospital for their medical treatment. The number of patients with active or inactive CD was controlled.

In accordance with French legislation and the Declaration of Helsinki, participants were fully informed about the purpose of the study, which was approved by the Ile-de-France Ethical Research Committee (no. 2015-09-05). Once all their questions about the study had been answered and they had given their written consent, they completed (in $25 \mathrm{~min}$ ) a paper-and-pencil questionnaire containing the measures outlined below.

\section{Measures}

Demographic and disease-related information included age, gender, marital status, years of education, employment status, and medical treatment.

Clinical activity of CD was assessed with the modified HarveyBradshaw activity index (HBAI; Harvey and Bradshaw, 1980) for CD patients. Patients with HBAI scores $\leq 4$ were classified as having an inactive disease.

Fatigue was assessed with the 9-item Fatigue Severity Scale (FSS). Items are rated on a 7-point scale ranging from (1) "disagree" to (7) "agree"; the fatigue threshold score is set at 36. The mean of the scores for the nine items represents a continuous variable with values ranging from 1 (no fatigue interference) to 7 (maximum fatigue interference). This scale has good psychometric properties (Whitehead, 2009) and is therefore one of the most commonly used self-report questionnaires to measure fatigue (Krupp et al., 1989; Opheim et al., 2014).

Anxiety and depression were assessed with the Hospital Anxiety and Depression Scale (HADS), which is a 14-item scale used as a brief instrument for detecting the intensity of depression and anxiety in patient populations (Zigmond and Snaith, 1983; Herman, 1997). The HADS has few somatic items so is unlikely 


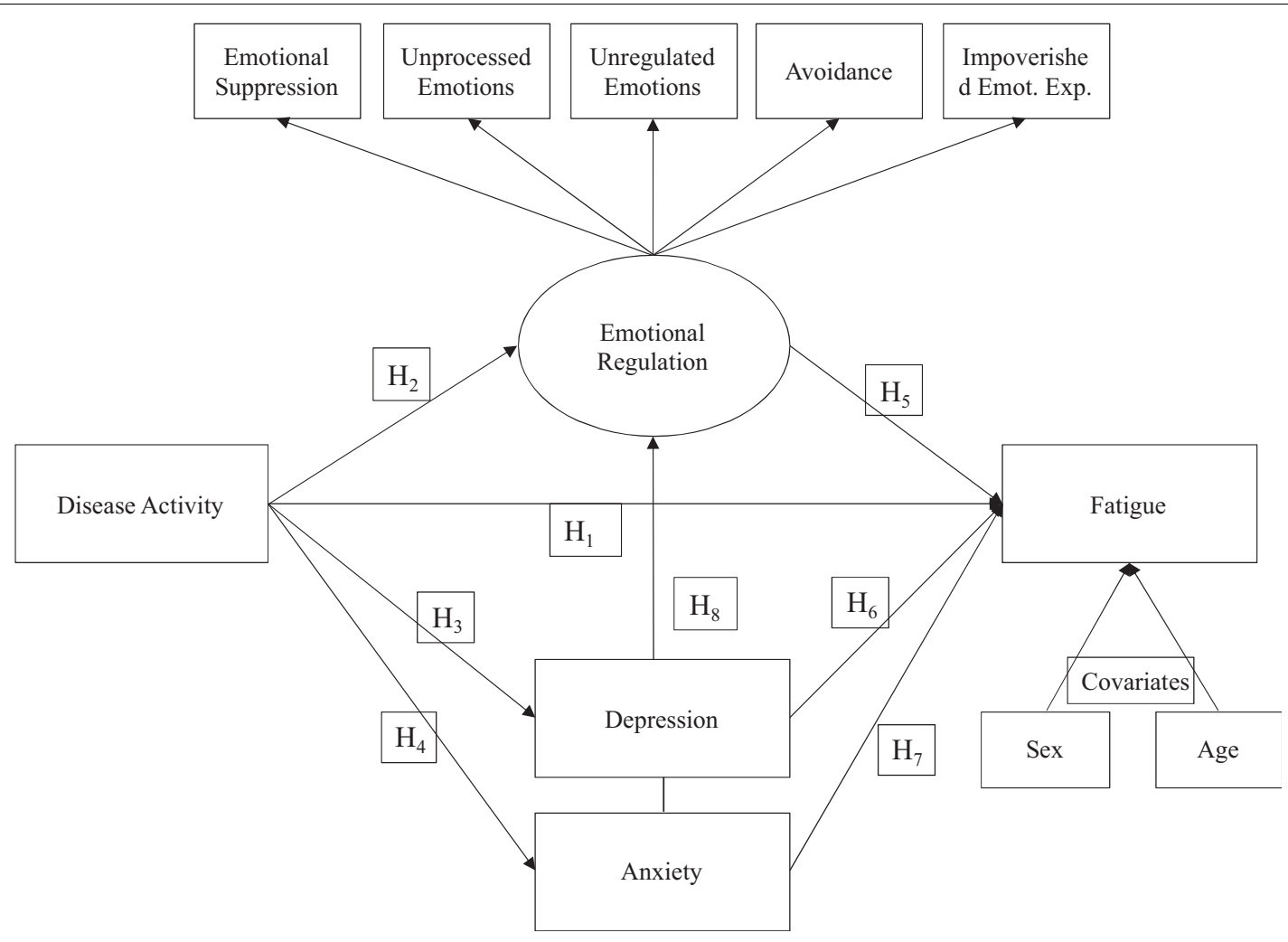

FIGURE 1 | Model synthesizing the study hypotheses.

to confuse depression with physical symptoms such as pain and fatigue. Scores for the depression and anxiety subscales can range from 0 to 21 , with a score $>10$ indicating probable anxiety or depression. The French adaptation of the HADS confirmed Zigmond and Snaith's original two-factor structure and has been shown to possess good psychometric properties. Internal reliability ranges from 0.79 to 0.90 for the anxiety subscale, and from 0.79 and 0.90 for the depression subscale. The correlation between the two subscales is significant but moderate $(r=0.46)$, representing $22 \%$ of the common variance (Lépine et al., 1985).

Emotional processing was assessed with the Emotional Processing Scale (EPS-25), which is a 25-item self-report questionnaire designed to identify and measure emotional processing styles and potential deficits in healthy individuals and those with psychological or physical disorders. It comprises five subscales, each with five items that are rated on a 10-point (0-9) attitudinal scale: suppression (excessive control of emotional experience and expression), signs of unprocessed emotion (intrusive and persistent emotional experiences), unregulated emotion (inability to control one's emotions), avoidance (avoidance of negative emotional triggers), impoverished emotional experience (detached experience of emotions due to poor emotional insight). Total score can range from 0 to 225, higher scores indicating poorer emotional processing. In the original English version of the EPS developed in the United Kingdom, these five factors explained $59.4 \%$ of the total variance, and overall internal reliability was high $(\alpha=0.92)$, ranging from 0.70 to 0.80 for the five factors. A French version has been developed (Gay et al., 2019).

\section{Data Analysis Plan}

First, some preliminary analyses were conducted (Student's $t$-test, correlations). To gain a better understanding of the characteristics of the sample, the differences in the mean scores of participants with active and inactive disease were calculated using Student's $t$-test. Next, to explore the bivariate relationships between the variables under study, zero-order correlations were calculated. Our research hypotheses were tested through a multiple mediation model using Amos 22 software. We evaluated model fit using the following indices: Carmines-McIver Index $\left(\chi^{2} / \mathrm{df}\right)$ (Carmines and McIver, 1981), the Non-Normed Fit Index (NNFI) (Jöreskog and Sörbom, 1996), the Comparative Fit Index (CFI) (Bentler, 1990), and the Root Mean Square Error of Approximation (RMSEA) (Browne and Cudeck, 1993). If the Carmines-McIver Index, which is the ratio between $\chi^{2}$ and degrees of freedom, has a value less than or equal to three, this indicates an excellent fit. For the other indices, to assess the adequacy of a model, Hu and Bentler (1999) proposed threshold values greater than or equal to 0.90 for the NNFI and CFI, and values less than or equal to 0.08 for the RMSEA. Finally, to verify the mediation effect, total and specific indirect effects were estimated using the bootstrap bias-correction method. 
TABLE 1 | Sociodemographic, health information and psychological distress (depression, anxiety, fatigue) data (number and percentage) psychological distress (depression, anxiety, fatigue) data (number and percentage).

\begin{tabular}{|c|c|}
\hline Gender & \\
\hline Women & $61(55.45 \%)$ \\
\hline Men & $49(44.55 \%)$ \\
\hline \multicolumn{2}{|l|}{ Medical treatment } \\
\hline Immunosuppressant & $4(3.64 \%)$ \\
\hline Anti-tnf & $67(60.91 \%)$ \\
\hline Immunosuppressant + Anti-tnf & $39(35.45 \%)$ \\
\hline \multicolumn{2}{|l|}{ Disease activity assessment $\mathrm{HBAI}$} \\
\hline Inactive $(x<4)$ & $55(50 \%)$ \\
\hline Light $(4 \leq x \leq 8)$ & $33(30 \%)$ \\
\hline Moderate $(8<x \leq 12)$ & $14(12,73 \%)$ \\
\hline Severe (>12) & $8(7.27 \%)$ \\
\hline \multicolumn{2}{|l|}{ Marital status } \\
\hline Married/couple & $60(54.55 \%)$ \\
\hline Single & $38(34.55 \%)$ \\
\hline Divorced & $9(8.18 \%)$ \\
\hline Widowhood & $1(0.91 \%)$ \\
\hline Unknown & $2(1.81 \%)$ \\
\hline \multicolumn{2}{|l|}{ Education } \\
\hline High school & $31(28.18 \%)$ \\
\hline Youth Training/BTEC First Diploma & $26(23.64 \%)$ \\
\hline College Degree or higher & $44(40 \%)$ \\
\hline No diploma & $9(8.18 \%)$ \\
\hline \multicolumn{2}{|l|}{ Employment } \\
\hline Full-time & $58(52.73 \%)$ \\
\hline Part-time & $14(12.73 \%)$ \\
\hline Unemployed & $11(10 \%)$ \\
\hline Students & $10(9.09 \%)$ \\
\hline Without professional activity & $6(5.45 \%)$ \\
\hline Disability & $10(9.09 \%)$ \\
\hline Sick leave & $1(0.91 \%)$ \\
\hline \multicolumn{2}{|l|}{ Psychological assessment } \\
\hline \multicolumn{2}{|l|}{ - Fatigue (FSS) } \\
\hline$x \leq 4$ & $44(40 \%)$ \\
\hline$x>4$ & $66(60 \%)$ \\
\hline \multicolumn{2}{|l|}{ - Depression (HAD-D) } \\
\hline None $(x<8)$ & $60(54.55 \%)$ \\
\hline Mild $(8 \leq x \leq 10)$ & $19(17.27 \%)$ \\
\hline Moderate $(11 \leq x \leq 14)$ & $28(25.45 \%)$ \\
\hline Severe $(x>14)$ & $3(2.73 \%)$ \\
\hline Total of depressed patients & $50(45.45 \%)$ \\
\hline \multicolumn{2}{|l|}{ - Anxiety (HAD-A) } \\
\hline None $(x<8)$ & $34(30.91 \%)$ \\
\hline Mild $(8 \leq x \leq 10)$ & $23(20.91 \%)$ \\
\hline Moderate $(11 \leq x \leq 14)$ & $36(32.73 \%)$ \\
\hline Severe $(x>14)$ & $17(15.45 \%)$ \\
\hline Total of anxious patients & $76(69.09 \%)$ \\
\hline
\end{tabular}

\section{RESULTS}

\section{Patients}

Participants had a mean age of 38.04 years $(S D=12.06)$, with a slight predominance of women $(55.45 \%)$; the majority were married or living with a partner (54.55\%), and $65.46 \%$ had a professional activity. $50 \%$ had a clinically active disease, and for $60 \%$ of those, the clinical activity was light.

In our sample, $60 \%$ reported a moderate fatigue $(M=4.55$, $S D=1.69$ ), and $69.09 \%$ reported anxiety. While patients reported moderate levels of anxiety, the prevalence in the sample was $69.09 \%$. Overall level of anxiety was low $(M=9.94, S D=4.68)$. Mean depression scores were low $(M=6.89, S D=4.45)$, although $45.45 \%$ of patients reported symptoms of depression.

Regarding emotional processing (see Table 2), the EPS25 total score indicated dysfunctional processing $(M=3.65$, $S D=1.88)$ compared to the general population $(M=2.51$, $S D=1.04)$, with the mean of the clinical sample nearing two standard deviations below the mean of healthy controls. All subscale scores were significantly different from those obtained by healthy controls (Gay et al., 2019), whether the disease was active or not: suppression $(M=4.89, S D=2.37$ vs. $M=3.38$, $S D=2.35)$, avoidance $(M=4.26, S D=2.10$ vs. $M=3.29$, $S D=1.97)$, unprocessed emotions $(M=4.92, S D=2.39$ vs. $M=3.85, S D=2.47)$, unregulated emotions $(M=3.94, S D=2.06$ vs. $M=2.74, S D=2.35)$, and impoverishment $(M=3.34$, $S D=2.14$ vs. $M=2, S D=1.89)$. The average scores obtained on the unprocessed emotions dimension were particularly high, indicating intrusive and persistent emotional experiences, which may be an indicator of a traumatic experience. Suppression of emotions also reflects the cost of trying to deal with emotions for these patients.

\section{Comparison of Patients With a Clinically Active and a Clinically Inactive Disease}

Results showed that there was no significant difference between anxiety scores of patients with an active disease and those with no disease activity: both groups reported clinical-level anxiety, with no decrease when the disease was no longer active. There were significant differences in fatigue and depression in relation to disease activity. Patients with an active disease reported significantly more fatigue and depression (see Table 2).

Regarding emotional processing, patients with an active disease had significantly more difficulty on all dimensions of emotional processing. Compared to patients with a clinically inactive disease, they showed greater avoidance of emotional triggers, had a more detached experience of emotions, exerted more control of emotional experience and expression, and showed a higher tendency to express anger.

Finally, it is important to note that scores for avoidance, emotional suppression and unprocessed emotion were particularly high in the active disease group. In other words, these patients had impoverished emotions, avoided negative stimuli, perceived events as significantly more external to them, and experienced more anger than patients with an inactive disease.

\section{Bivariate Relations Between Variables}

We analyzed the bivariate relationships between age, sex, Disease Activity, depression, anxiety, the total score of the emotional processing variable and its five dimensions (Emotional suppression, Unprocessed emotions, Unregulated emotions, Avoidance, Impoverished emotional experience) and fatigue. The 
TABLE 2 | Psychological assessments (mean scores and SD) for the whole sample and significant differences between patients with active and inactive disease.

\begin{tabular}{|c|c|c|c|c|c|}
\hline & All sample mean (SD) & Active disease mean (SD) & Inactive disease mean (SD) & $t$ & $p$ \\
\hline Age & $38.04(12.06)$ & $38.84(12.64)$ & $37.25(11.53)$ & 0.68 & n.s. \\
\hline HADS-D & $6.89(4.45)$ & $8.49(4.01)$ & $5.29(4.32)$ & 4.02 & $<0.001$ \\
\hline HADS-A & $9.94(4.68)$ & $10.51(4.14)$ & $9.36(5.14)$ & 1.28 & n.s. \\
\hline FSS & $4.55(1.69)$ & $5.21(1.36)$ & $3.88(1.68)$ & 4.47 & $<0.001$ \\
\hline Emotional processing & $3.65(1.88)$ & $4.27(1.73)$ & $3.05(1.84)$ & 3.50 & $<0.001$ \\
\hline - Suppression & $4.12(2.47)$ & $4.89(2.37)$ & $3.38(2.35)$ & 3.30 & $<0.001$ \\
\hline - Unprocessed emotion & $4.38(2.44)$ & $4.92(2.39)$ & $3.85(2.47)$ & 2.29 & $<0.05$ \\
\hline - Unregulated emotion & $3.33(2.29)$ & $3.94(2.06)$ & $2.74(2.35)$ & 2.77 & $<0.01$ \\
\hline - Avoidance & $3.76(2.08)$ & $4.26(2.10)$ & $3.29(1.97)$ & 2.45 & $<0.01$ \\
\hline - Impoverished emotion & $2.66(2.12)$ & $3.34(2.14)$ & $2(1.89)$ & 3.42 & $<0.001$ \\
\hline
\end{tabular}

TABLE 3 | Pearson's $r$ correlations of variables $(n=110)$.

\begin{tabular}{|c|c|c|c|c|c|c|c|c|c|c|c|c|c|}
\hline & & 1 & 2 & 3 & 4 & 5 & 6 & 7 & 8 & 9 & 10 & 11 & 12 \\
\hline 1 & $\operatorname{Sex}(0=F, 1=M)$ & 1 & & & & & & & & & & & \\
\hline 2 & Age & 0.006 & 1 & & & & & & & & & & \\
\hline 3 & Disease activity $(0=$ Not, $1=$ Yes) & -0.018 & 0.066 & 1 & & & & & & & & & \\
\hline 4 & HADS-D & -0.088 & -0.186 & $0.361^{\star \star}$ & 1 & & & & & & & & \\
\hline 5 & HADS-A & 0.153 & $-0.194^{\star}$ & 0.123 & $0.517^{\star \star}$ & 1 & & & & & & & \\
\hline 6 & Emotional processing (Total) & 0.091 & 0.003 & $0.325^{\star \star}$ & $0.238^{\star}$ & 0.160 & 1 & & & & & & \\
\hline 7 & - Emotional suppression & 0.011 & $-0.188^{\star}$ & $0.308^{\star \star}$ & $0.302^{\star \star}$ & 0.056 & $0.790^{\star \star}$ & 1 & & & & & \\
\hline 8 & - Unprocessed emotions & 0.166 & 0.076 & $0.219^{*}$ & 0.143 & 0.150 & $0.858^{\star \star}$ & $0.636^{\star \star}$ & 1 & & & & \\
\hline 9 & - Unregulated emotions & 0.024 & -0.026 & $0.263^{\star \star}$ & $0.214^{*}$ & 0.141 & $0.793^{\star \star}$ & $0.475^{\star \star}$ & $0.627^{\star \star}$ & 1 & & & \\
\hline 10 & - Avoidance & 0.187 & 0.103 & $0.234^{\star}$ & 0.129 & 0.112 & $0.831^{\star \star}$ & $0.525^{\star \star}$ & $0.628^{\star \star}$ & $0.559^{\star \star}$ & 1 & & \\
\hline 11 & - Impoverished emotional experience & -0.011 & 0.072 & $0.318^{\star \star}$ & 0.184 & 0.149 & $0.865^{\star \star}$ & $0.589^{\star \star}$ & $0.628^{\star \star}$ & $0.625^{\star \star}$ & $0.775^{\star \star}$ & 1 & \\
\hline 12 & FSS_(Total) & $0.249^{\star *}$ & 0.033 & $0.395^{\star \star}$ & $0.414^{* *}$ & $0.257^{\star \star}$ & $0.465^{\star \star}$ & $0.374^{\star *}$ & $0.415^{\star \star}$ & $0.319^{* *}$ & $0.445^{\star \star}$ & $0.370^{\star \star}$ & 1 \\
\hline
\end{tabular}

${ }^{*} p<0.05 ;{ }^{* *} p<0.01$.

results are shown in Table 3. Gender was positively associated with the total fatigue score $(r=0.25, p<0.01)$, women having higher scores than men. The younger participants had higher scores for anxiety $(r=-0.19, p<0.05)$ and emotional suppression $(r=-0.19, p<0.05)$. Furthermore, Disease activity was positively correlated with depression $(r=0.36, p<0.01)$, emotional processing $(r=0.32, p<0.01)$, and fatigue $(r=0.39$, $p<0.01)$, but not with anxiety $(r=0.12, p=$ n.s.). In fact, the only variable that correlated significantly with anxiety was fatigue. Finally, emotional processing was positively correlated with fatigue $(r=0.46, p<0.01)$.

\section{Testing the Multiple Mediation Model}

Figure 2 shows our final model, without the anxiety variable. Although an anxiety-mediating effect was hypothesized in the relationship between Disease activity and Fatigue, we were unable to obtain a model that showed adequate fit indices and with significant structural parameters of the relationship between Disease activity and anxiety and between anxiety and fatigue. Therefore, as partially expected, our results showed a partial mediation model, indicating suitable fit indexes: $\mathrm{X}^{2}=24.16$, $\mathrm{df}=22, \mathrm{X}^{2} / \mathrm{df}=1.10, \mathrm{NNFI}=0.98, \mathrm{CFI}=0.99$, and $\mathrm{RMSEA}=0.03$ (Low $=0.00$, High $=0.089)$. Disease activity was positively associated with fatigue $(\beta=0.18, p<0.01)$, depression $(\beta=0.36$, $p<0.001)$, and Emotional regulation $(\beta=0.33, p<0.001)$.
Moreover, emotional regulation $(\beta=0.31, p<0.001)$ and Depression $(\beta=0.32, p<0.001)$ were associated with fatigue. The model explained $40 \%$ of fatigue variance.

Table 4 shows total and specific indirect effects of the model. The 95\% bootstrap confidence interval for the total indirect effect did not include zero (C.I. $=0.064 ; 0.338$ ), as well as confidence intervals for specific indirect effects (C.I. $=0.032 ; 0.204$ for Emotional regulation, and C.I. $=0.057 ; 0.217$ for Depression), suggesting a significant partial mediation effect.

\section{DISCUSSION}

The main objective of this research was to examine the role of specific psychological factors (anxiety, depression, and emotional processing) underlying CD-related fatigue.

These preliminary results confirmed all the predictions, except the expected positive link between disease activity and anxiety. This could be explained by the prevalence of CD patients with anxiety symptoms in our sample $(69.09 \%$, which is high but still within the upper limits observed elsewhere: Mikocka-Walus et al., 2016; Neuendorf et al., 2016). This suggests that CD patients experiencing anxiety are caught in a vicious circle, in which disease activity does not worsen but only confirms their negative expectations. The other aspects of the psychological profile of CD patients were consistent with the literature: half 


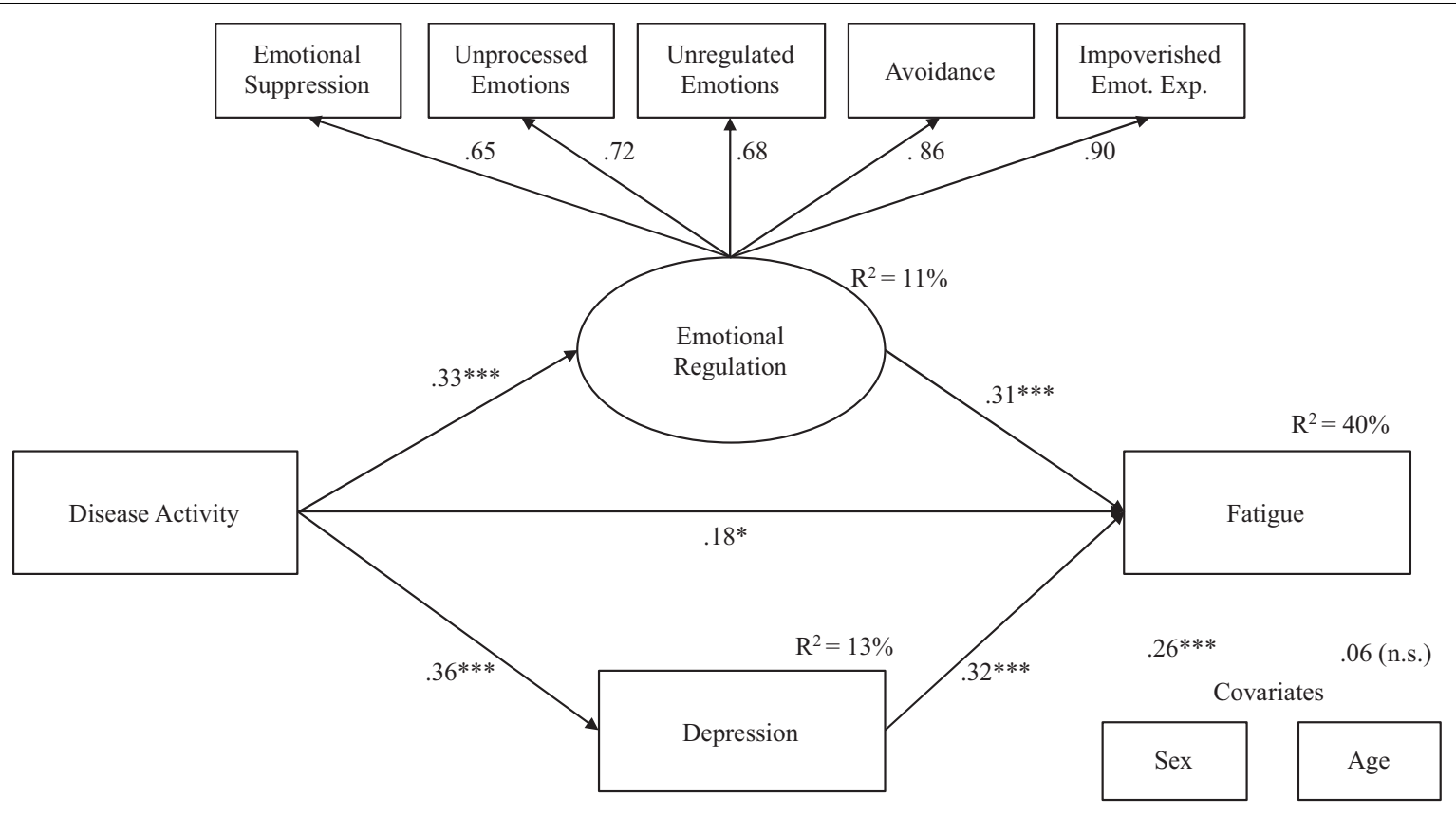

FIGURE 2 | Mediation model: indirect effects of Disease Activity on Fatigue through Emotional processing and Depression.

TABLE 4 | Total and specific indirect effect of mediation model.

\begin{tabular}{lccccc}
\hline Total indirect effect & \multicolumn{3}{c}{ Product of coefficients } & & \multicolumn{2}{c}{ Bootstrapping bias-corrected 95\% Cl } \\
\cline { 2 - 4 } Relationship & Estimate & SE & $\boldsymbol{p}$ & & Lower limit \\
\hline Disease activity to fatigue & 0.220 & 0.064 & $<0.001$ & 0.125 & 0.338 \\
Emotional regulation & 0.116 & 0.047 & $<0.001$ & 0.057 & 0.217 \\
Depression & 0.103 & 0.052 & $<0.001$ & 0.033 & 0.204 \\
\hline
\end{tabular}

of the patients had depressive disorders [which is high, but, like anxiety, is within the levels observed elsewhere, cf. MikockaWalus et al., 2016; Neuendorf et al., 2016], and two-thirds showed pathological anxiety. The EPS-25 total score indicated dysfunctional processing compared to the general population, with the mean of the clinical sample nearing two standard deviations below that of healthy controls. CD patients had great difficulty dealing with their emotions, with extensive emotional avoidance, suppression and impoverishment. Their scores on the subscales of unregulated emotion (whose main manifestation is anger) and unprocessed emotions (whose manifestations are rumination and intrusive thoughts) also suggest poor emotional processing. When the disease was active, patients reported significantly more fatigue and depression; their difficulty dealing with emotions increased significantly, suggesting a traumatic state with greater reactivity to and dysfunctional control of emotional stimuli.

The present preliminary study thus indicates that disease activity, depression, and emotional processing all predict CDrelated fatigue. Moreover, and importantly, the study found both direct and indirect relations between disease activity and fatigue. First, in line with past studies (Czuber-Dochan et al., 2013a; Huppertz-Hauss et al., 2017), the relationship between CD activity and CD-related fatigue was mediated by the severity of depressive symptoms. Secondly, the most novel finding of the present study is that the relationship was also mediated by the efficiency of emotional processing. This twoway model, which explained $40 \%$ of the variance, could be consistent with the idea of the overwhelming consequences of disease activity, which simultaneously is related to psychological breakdown (i.e., depression) or to impaired emotional processing in many individuals could explain a part of CD related fatigue. Lastly, the most surprising result is the lack of link between depression and emotional processing in the multiple mediation model tested. From a theoretical point of view, this lack is unexpected because depression is related to dysfunctional emotional regulation processing (Rachman, 1980; Teasdale, 1999; Trindade et al., 2017).

The present preliminary results shed further light on the observation that some CD patients continue to experience fatigue when they are in remission. Our results confirm that this fatigue is likely to be maintained not only by the persistence of depressive symptoms, but also, and importantly, by poor emotional processing of the negative experiences that are inevitably associated with medical conditions like CD. Indeed, while remission might allow some patients to regulate their emotions 
effectively and thus to implement effective psychological adjustment strategies, for others, somewhat ironically, remission may increase anxiety about possible relapse. This might explain the ongoing difficulty dealing with their emotions and why CDrelated fatigue persists or even worsens. However, future research is required to address these possibilities, both in CD and in other chronic medical conditions (Menting et al., 2018).

The present study has a number of limitations. The lack of a control group and of a second assessment prevents a detailed understanding of how and to what extent emotional processing is impaired by the clinical activity of the disease, and how and to what extent experiencing a chronic disability disease disrupts emotional processing. It thus remains possible that reverse effects could be observed in patients with a disease that becomes inactive, and/or in patients who are less impaired by the severity of CD-related fatigue. A longitudinal study should therefore be conducted to better understand how patients deal with fatigue and emotional processing over time, which may also provide a better understanding of the role of anxiety over time. Finally, emotional processing and depression in CD patients could be mediated by other relevant psychological factors such as coping strategies. Emotional processing would probably play as essential a role in depression as the modalities of patients' psychological adjustment. Patients would have to deal with physical difficulties and self-related negative cognitions due to the discrepancies between their actual and desired states (Czuber-Dochan et al., 2013b; Wåhlin et al., 2019). Depression could occur not only because of dysfunctional processing of emotions (Wilkinson et al., 2019), but also because of inoperative coping strategies leading to emotional overload, which would lead to increased fatigue. Further research is necessary to test a causal and more complex model of CD related fatigue. Despite these limitations, the present study clearly points to emotional processing as an important factor in the relationship between CD activity and CD-related fatigue. It would also be important to consider the duration of the disease (taking account relapses, major changes in the management of the $\mathrm{CD}$ for example) and the time of the disease's onset (childhood, adolescence, adulthood), as these may have outcomes on emotional processing and on fatigue (Hughes et al., 2012; Mikocka-Walus et al., 2016). A better understanding of how $\mathrm{CD}$ patients process their emotions could also clarify why some

\section{REFERENCES}

Abautret-Daly, Á, Dempsey, E., Parra-Blanco, A., Medina, C., and Harkin, A. (2018). Gut-brain actions underlying comorbid anxiety and depression associated with inflammatory bowel disease. Acta Neuropsychiatr. 30, 275-296. doi: 10.1017/neu.2017.3

Artom, M., Czuber-Dochan, W., Sturt, J., Murrells, T., and Norton, C. (2017). The contribution of clinical and psychosocial factors to fatigue in 182 patients with inflammatory bowel disease: a crosssectional study. Aliment. Pharmacol. Ther. 45, 403-416. doi: 10.1111/apt. 13870

Artom, M., Czuber-Dochan, W., Sturt, J., and Norton, C. (2016). Targets for health interventions for inflammatory bowel disease-fatigue. J. Crohns Colitis 10, 860-869. doi: 10.1093/ecco-jcc/jjw029 patients appear more resilient to CD-related depression and fatigue than others.

Given this newly established role of emotional processing, it is likely that acceptance and commitment therapy could offer effective management strategies for CD patients (Wynne et al., 2019). This would help individuals to experience their emotions, thoughts, and bodily sensations fully without trying to change, control, or avoid them (Hayes et al., 1999). Several recent studies have shown that this approach can lead to positive outcomes in individuals with depression and anxiety (Twohig and Levin, 2017). Acceptance can also help individuals with chronic pain and fatigue to adjust and function better (Hughes et al., 2017; Jacobsen et al., 2017). It would therefore be very relevant for future research to investigate the extent to which acceptance and commitment therapy could help CD patients cope with depression and fatigue.

\section{DATA AVAILABILITY STATEMENT}

All datasets generated for this study are included in the article/supplementary material.

\section{ETHICS STATEMENT}

The studies involving human participants were reviewed and approved by the Ile-de-France Ethical Research Committee (no. 2015-09-05). The patients/participants provided their written informed consent to participate in this study.

\section{AUTHOR CONTRIBUTIONS}

IB and MC-G: substantial contributions to the conception or design of the work, analysis or interpretation of data for the work. LM and MD-B: the acquisition of data for the work and they organized the database. FS: analysis or interpretation of data for the work, he performed the statistical analysis. LB and GS: substantial contributions to the acquisition of data for the work. IB, FS, MC-G, GS, and LB wrote sections of the manuscript. All authors contributed to manuscript revision, read and approved the submitted version.

Baker, R., Thomas, S., Thomas, P. W., Gower, P., Santonastaso, M., and Whittlesea, A. (2010). The emotional processing scale: scale refinement and abridgement (EPS-25). J. Psychosom. Res. 68, 83-88. doi: 10.1016/j.jpsychores.2009.07.007

Banovic, I., Gilibert, D., Jebrane, A., and Cosnes, J. (2012). Personality and fatigue perception in a sample of IBD outpatients in remission: a preliminary study. J. Crohns Colitis 6, 571-577. doi: 10.1016/j.crohns.2011.11.006

Bentler, P. (1990). Comparative fit indexes in structural models. Psychol. Bull. 107, 238-246. doi: 10.1037/0033-2909.107.2.238

Borren, N. Z., van der Woude, C. J., and Ananthakrishnan, A. N. (2019). Fatigue in IBD: epidemiology, pathophysiology and management. Nat. Rev. Gastro. Hepat. 16, 247-259. doi: 10.1038/s41575-018-0091-9

Browne, M. W., and Cudeck, R. (1993). "Alternative ways of assessing model fit," in Testing Structural Equation Models, eds K. A. Bollen and J. S. Long (Newbury Park, CA: Sage), 136-162. 
Carmines, E. G., and McIver, J. P. (1981). “Analyzing models with unobserved variables," in Social Measurement: Current Issues, eds G. W. Bohrnstedt and E. F. Borgatta (Beverly Hills: Sage).

Czuber-Dochan, W., Dibley, L. B., Terry, H., Ream, E., and Norton, C. (2013a). The experience of fatigue in people with inflammatory bowel disease: an exploratory study. J. Adv. Nurs. 69, 1987-1999. doi: 10.1111/jan.12060

Czuber-Dochan, W., Ream, E., and Norton, C. (2013b). Review article: description and management of fatigue in inflammatory bowel disease. Aliment. Pharm. Ther. 37, 505-516. doi: 10.1111/apt.12205

Dignass, A., Van Assche, G., Lindsay, J. O., Lémann, M., Söderholm, J., Colombel, J. F., et al. (2010). The second european evidence-based consensus on the diagnosis and management of Crohn's disease: current management. J. Crohns Colitis 4, 28-62. doi: 10.1016/j.crohns.2009.12.002

Gay, M. C., Baker, R., Vrignaud, P., Thomas, P., Heinzlef, O., Haag, P., et al. (2019). Cross-cultural validation of a french version of the emotional processing scale (EPS-25). Eur. Rev. Appl. Psychol. 69, 91-99. doi: 10.1016/j.erap.2019.05.002

Gay, M. C., Bungener, C., Thomas, S., Vrignaud, P., Thomas, P., Heinzlef, O., et al. (2017). Anxiety, emotional processing and depression in patients with multiple sclerosis. BMC Neurol. 17:43. doi: 10.1186/s12883-017-0803-8

Gay, M. C., Vrignaud, P., Garitte, C., and Meunier, C. (2010). Predictors of depression in multiple sclerosis. Acta Neurol. Scand. 121, 161-170. doi: 10.1111/ j.1600-0404.2009.01232.x

Goodhand, J., Wahed, M., Mawdsley, J. E., Farmer, A. D., Aziz, Q., and Rampton, D. S. (2012). Mood disorders in inflammatory bowel disease: relation to diagnosis, disease activity, perceived stress, and other factors. Inflamm. Bowel. Dis. 18, 2301-2309. doi: 10.1002/ibd.22916

Graff, L. A., Clara, I., Walker, J. R., Lix, L., Carr, R., Miller, N., et al. (2013). Changes in fatigue over 2 years are associated with activity of inflammatory bowel disease and psychological factors. Clin. Gastroenterol. H 11, 1140-1146. doi: 10.1016/j.cgh.2013.03.031

Harvey, R. F., and Bradshaw, J. M. (1980). A simple index of Crohn's-disease activity. Lancet 315:514.

Hayes, S. C., Bissett, R., Korn, Z., Zettle, R. D., Rosenfarb, I., Cooper, L., et al. (1999). The impact of acceptance versus control rationales on pain tolerance. Psychol. Record 49, 33-47.

Herman, C. (1997). International experience with the hospital anxiety and depression scale. a review of validation date and clinical results. J. Psychosom. Res. 42, 17-41. doi: 10.1016/S0022-3999_96_00216-4

$\mathrm{Hu}, \mathrm{L}$., and Bentler, P. (1999). Cutoff criteria for fit indexes in covariance structure analysis: conventional criteria versus new alternatives. Struct. Equ. Modeling 6, 1-55. doi: 10.1080/10705519909540118

Hughes, A. E., Berg, C. A., and Wiebe, D. J. (2012). Emotional processing and self-control in adolescents with type 1 diabetes. J. Ped. Psychol. 37, 925-934. doi: 10.1093/jpepsy/jss062

Hughes, L. S., Clark, J., Colclough, J. A., Dale, E., and McMillan, D. (2017). Acceptance and commitment therapy (ACT) for chronic pain. Clin. J. Pain 33, 552-568. doi: 10.1097/AJP.0000000000000425

Huppertz-Hauss, G., Høivik, M. L., Jelsness-Jørgensen, L. P., Opheim, R., Henriksen, M., Høie, O., et al. (2017). Fatigue in a population-based cohort of patients with inflammatory bowel disease 20 years after diagnosis: The IBSEN study. Scand. J. Gastroentero 52, 351-358. doi: 10.1080/00365521.2016.1256425

Jacobsen, H. B., Kallestad, H., Landrø, N. I., Borchgrevink, P. C., and Stiles, T. C. (2017). Processes in acceptance and commitment therapy and the rehabilitation of chronic fatigue. Scand. J. Psychol. 58, 211-220. doi: 10.1111/sjop.12363

Jelsness-Jørgensen, L. P., Bernklev, T., Henriksen, M., Torp, R., and Moum, B. A. (2011). Chronic fatigue is more prevalent in patients with inflammatory bowel disease than in healthy controls. Inflamm. Bowel. Dis. 17, 1564-1572. doi: 10.1002/ibd. 21530

Jöreskog, K. G., and Sörbom, D. (1996). LISREL 8: User's Reference Guide, 2nd Edn. Chicago: Scientific Software International.

Keeton, R. L., Mikocka-Walus, A., and Andrews, J. M. (2015). Concerns and worries in people living with inflammatory bowel disease (IBD): a mixed methods study. J. Psychosom. Res. 78, 573-578. doi: 10.1016/j.jpsychores.2014. 12.004

Krupp, L. B., LaRocca, N. G., Muir-Nash, J., and Steinberg, A. D. (1989). The fatigue severity scale: application to patients with multiple sclerosis and systemic lupus erythematosus. Arch. Neurol Chicago 46, 1121-1123. doi: 10.1001/archneur. 1989.00520460115022

Lépine, J. P., Godchau, M., Brun, P., and Lempérière, T. (1985). Évaluation de l'anxiété et de la dépression chez des patients hospitalisés dans un service de médecine interne. Ann. Med. Psychol. 143, 175-189.

Menting, J., Tack, C. J., Bleijenberg, G., Donders, R., Droogleever Fortuyn, H. A., Fransen, J., et al. (2018). Is fatigue a disease-specific or generic symptom in chronic medical conditions? Health Psychol. 37, 530-543. doi: 10.1037/ hea0000598.supp

Mikocka-Walus, A., Knowles, S. R., Keefer, L., and Graff, L. (2016). Controversies revisited: a systematic review of the comorbidity of depression and anxiety with inflammatory bowel diseases. Inflamm. Bowel Dis. 22, 752-762. doi: 10.1097/ MIB.0000000000000620

Neuendorf, R., Harding, A., Stello, N., Hanes, D., and Wahbeh, H. (2016). Depression and anxiety in patients with inflammatory bowel disease: a systematic review. J. Psychosom. Res. 87, 70-80. doi: 10.1016/j.jpsychores.2016. 06.001

Opheim, R., Fagermoen, M. S., Bernklev, T., Jelsness-Jorgensen, L. P., and Moum, B. (2014). Fatigue interference with daily living among patients with inflammatory bowel disease. Qual. Life Res. 23, 707-717. doi: 10.1007/s11136013-0508-4

Rachman, S. J. (1980). Emotional processing. Behav. Res. Ther. 18, 51-60.

Teasdale, J. D. (1999). Emotional processing, three modes of mind and the prevention of relapse in depression. Behav. Res. Ther. 37, S53-S77.

Trindade, I. A., Ferreira, C., Moura-Ramos, M., and Pinto-Gouveia, J. (2017). An 18-month study of the effects of IBD symptomatology and emotion regulation on depressed mood. Int. J. Colorectal Dis. 32, 651-660. doi: 10.1007/s00384017-2774-z

Twohig, M. P., and Levin, M. E. (2017). Acceptance and commitment therapy as a treatment for anxiety and depression: a review. Psychiatr. Clin. North Am. 40, 751-770. doi: 10.1016/j.psc.2017.08.009

van Langenberg, D. R., and Gibson, P. R. (2014). Factors associated with physical and cognitive fatigue in patients with Crohn's disease: a cross-sectional and longitudinal study. Inflamm. Bowel Dis. 20, 115-125. doi: 10.1097/01.MIB. 0000437614.91258 .70

Wåhlin, M., Stjernman, H., and Munck, B. (2019). Disease-related worries in persons with crohn disease: an interview study. Gastroenterol. Nurs. 42, 435442. doi: 10.1097/SGA.0000000000000395

Whitehead, L. (2009). The measurement of fatigue in chronic illness: a systematic review of unidimensional and multidimensional fatigue measures. J. Pain Symptom Manag. 37, 107-128. doi: 10.1016/j.jpainsymman.2007. 08.019

Wilkinson, B., Trick, L., Knight, A., Valton, V., Goodhand, J., Kennedy, N. A., et al. (2019). Factors associated with depression in people with inflammatory bowel disease: the relationship between active disease and biases in neurocognitive processing. Neurogastroenterol. Motil. 31:e13647. doi: 10.1111/nmo. 13647

Wynne, B., McHugh, L., Gao, W., Keegan, D., Byrne, K., Rowan, C., et al. (2019). Acceptance and commitment therapy reduces psychological stress in patients with inflammation bowel disease. Gastroenterology 156, 935-945. doi: 10.1053/ j.gastro.2018.11.030

Zigmond, A. S., and Snaith, R. P. (1983). The hospital anxiety and depression scale. Acta Psychiat. Scand. 67, 361-370. doi: 10.1111/j.1600-0447.1983.tb09716.x

Conflict of Interest: The authors declare that the research was conducted in the absence of any commercial or financial relationships that could be construed as a potential conflict of interest.

Copyright (c) 2020 Banovic, Montreuil, Derrey-Bunel, Scrima, Savoye, Beaugerie and Gay. This is an open-access article distributed under the terms of the Creative Commons Attribution License (CC BY). The use, distribution or reproduction in other forums is permitted, provided the original author(s) and the copyright owner(s) are credited and that the original publication in this journal is cited, in accordance with accepted academic practice. No use, distribution or reproduction is permitted which does not comply with these terms. 